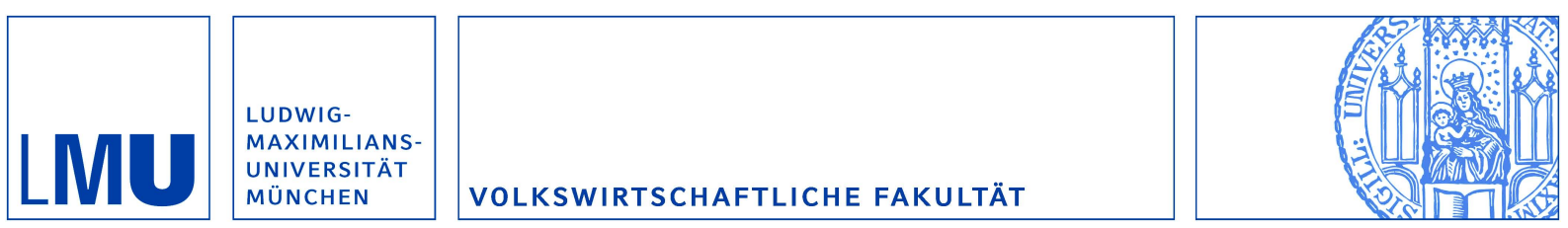

Haufler, Andreas und Wooton, lan:

Competition for Firms in an Oligopolistic Industry: Do Firms or Countries Have to Pay?

Munich Discussion Paper No. 2007-13

Department of Economics

University of Munich

Volkswirtschaftliche Fakultät

Ludwig-Maximilians-Universitäł München

Online at https://doi.org/10.5282/ubm/epub. 1399 


\title{
Competition for Firms in an Oligopolistic Industry: Do Firms or Countries Have to Pay?*
}

\author{
Andreas Haufler \\ Ian Wooton \\ University of Munich and CESifo University of Strathclyde and CESifo
}

March 2007

\begin{abstract}
We set up a model of generalised oligopoly where two countries of different size compete for an exogenous, but variable, number of identical firms. The model combines a desire by national governments to attract internationally mobile firms with the existence of location rents that arise even in a symmetric equilibrium where firms are dispersed. As economic integration proceeds, equilibrium taxes decline, switching from positive to negative levels, and then rise as trade costs fall even further. A range of trade costs is identified where economic integration raises the welfare of the small country, but lowers welfare in the large country.
\end{abstract}

Keywords: tax and subsidy competition, oligopolistic markets

JEL Classification: H25, H73, F15, F23

*We thank Rainald Borck, Ben Ferrett, Kai Konrad and participants at the Asia Pacific Trade Seminar, Kobe and in seminars at Berlin, Munich and Nuremberg for helpful discussions. This paper was started when the second author visited the Center for Economic Studies at the University of Munich and continued when the first author was visiting the University of Strathclyde. We thank both institutions for their hospitality. 


\section{Introduction}

The rise in foreign direct investment and the increasing role played by large, multinational firms have been amongst the most important developments in the world economy over the last three decades. These changes have had profound effects on the overall stance that governments have taken towards the location of mobile firms in their jurisdictions. This is reflected in the policies adopted to influence the investment decisions of these firms.

One policy area where these developments can be seen is in corporate taxation. Table 1 shows that nominal and effective average rates of corporation tax have fallen significantly over the last two decades. Moreover the figures in the table are likely to overestimate the taxes actually paid by mobile, multinational firms. Hines (2005), for example, presents evidence that the effective tax rates paid by U.S.-based multinationals have fallen more strongly during the period 1982-1999 than their host countries' statutory tax rates. This indicates that multinationals have been able to shift part of their profits to low-cost countries, or that they receive specific tax breaks in the host countries (or both). ${ }^{1}$

A second policy area where an increased "bargaining power" of mobile firms vis-à-vis host governments appears is state aid for the location of new plants or the expansion of existing ones. Such investment subsidies have become commonplace, in particular in sectors that combine the use of modern technologies with the creation of new jobs. This is well documented in the European Union (EU), where state aid given by member states to individual enterprises in their jurisdiction must be approved by the European Commission. Table 2 lists 15 cases in the years 2001-2004 alone where substantial investment subsidies, typically accounting for 10-30\% of the present value of the investment, have been approved by the EU Commission. ${ }^{2}$

\footnotetext{
${ }^{1}$ There is growing empirical evidence for profit shifting by multinationals; see Hines (1999) for a survey. Discriminatory tax breaks granted to multinational firms are a major current policy issue at both the OECD and the EU level. The EU's Primarolo Report (1999) and the OECD (2000) list many examples of discriminatory tax preferences in favour of multinational enterprises.

${ }^{2}$ Note that the subsidy payments collected in Table 2 cover only direct monetary transfers and thus represent merely a lower bound for the overall value of the incentive package. The latter often includes additional measures, such as the free provision of public infrastructure. See Davies (2005,
} 
Table 1: Corporate taxation in OECD countries

\begin{tabular}{|l|ccc|ccc|}
\hline & \multicolumn{3}{|c|}{ statutory $^{\text {tax rate }^{a}}$} & \multicolumn{3}{c|}{ effective $^{\text {average tax rate }}{ }^{b}$} \\
& 1985 & 1995 & 2005 & 1985 & 1995 & 2005 \\
\hline large countries (> 20 million) \\
Australia & 50 & 36 & 30 & 37 & 31 & 26 \\
Canada & 45 & 36 & 36 & 28 & 28 & 28 \\
France & 50 & 37 & 34 & 34 & 27 & 25 \\
Germany & 63 & 57 & 38 & 45 & 41 & 32 \\
Italy & 46 & 52 & 37 & 31 & 36 & 26 \\
Japan & 56 & 50 & 40 & 45 & 40 & 32 \\
Spain & 35 & 35 & 35 & 27 & 24 & 26 \\
United Kingdom & 40 & 33 & 30 & 28 & 26 & 24 \\
United States & 50 & 39 & 39 & 32 & 29 & 29 \\
\hline$\varnothing$ large countries & 48.3 & 41.7 & 35.4 & 34.1 & 31.3 & 27.6 \\
\hline small countries $(<\mathbf{2 0}$ million) & & & \\
Austria & 61 & 34 & 25 & 37 & 24 & 22 \\
Belgium & 45 & 40 & 34 & 35 & 31 & 26 \\
Finland & 60 & 25 & 26 & 45 & 19 & 21 \\
Greece & 44 & 40 & 32 & 36 & 33 & 21 \\
Ireland & 10 & 10 & 13 & 5 & 8 & 11 \\
Netherlands & 43 & 35 & 32 & 34 & 28 & 25 \\
Norway & 51 & 28 & 28 & 36 & 24 & 24 \\
Portugal & 55 & 40 & 28 & 48 & 29 & 20 \\
Sweden & 60 & 28 & 28 & 45 & 21 & 21 \\
Switzerland & 35 & 35 & 34 & 26 & 26 & 25 \\
\hline$\varnothing$ small countries & 46.4 & 31.5 & 28.0 & 34.7 & 24.3 & 21.6 \\
\hline \hline$\varnothing$ all countries ${ }^{c}$ & 47.3 & 36.3 & 31.5 & 34.4 & 27.6 & 24.4 \\
\hline
\end{tabular}

${ }^{a}$ including local taxes

${ }^{b}$ base case: real discount rate: $10 \%$, inflation rate: $3.5 \%$, depreciation rate: $12.25 \%$, rate of economic rent: 10\% (financial return: 20\%)

${ }^{c}$ unweighted average

Source: Devereux et al. (2002) 
Table 2: Approved investment subsidies in EU member states (2001-2004)

\begin{tabular}{|l|c|l|c|c|}
\hline Company $\left(\right.$ sector $\left.^{a}\right)$ & $\begin{array}{c}\text { Date of } \\
\text { approval }\end{array}$ & $\begin{array}{l}\text { Host country } \\
\text { (city/region) }\end{array}$ & $\begin{array}{c}\text { State aid } \\
\left(\text { million } €^{b}\right)\end{array}$ & $\begin{array}{c}\text { Aid inten- } \\
\text { sity }(\%)^{c}\end{array}$ \\
\hline \hline Nissan & $01 / 2001$ & U.K. (Sunderland) & 60 & 18.6 \\
Volkswagen & $07 / 2001$ & Germany (Dresden) & 75 & 12.3 \\
Daimler Chrysler & $12 / 2001$ & Germany (Thuringia) & 57 & 30.9 \\
Infineon (semiconductors) & $04 / 2002$ & Germany (Saxony) & 219 & 19.8 \\
ST Microelectronics & $04 / 2002$ & Italy (Sicily) & 542 & 26.3 \\
Renault & $06 / 2002$ & Spain (Valladolid) & 18 & 14.3 \\
Vauxhall & $09 / 2002$ & U.K. (Ellesmere Port) & 15 & 6.4 \\
Iveco (utility vehicles) & $10 / 2002$ & Italy (Puglia) & 109 & 44.0 \\
BMW & $12 / 2002$ & Germany (Leipzig) & 363 & 30.1 \\
Solar World (solar cells) & $03 / 2003$ & Germany (Saxony) & 73 & 35.0 \\
BMW & $05 / 2003$ & Austria (Steyr) & 16 & 15.3 \\
Volkswagen & $06 / 2003$ & Spain (Navarra) & 20 & 6.4 \\
AMD (microelectronics) & $02 / 2004$ & Germany (Saxony) & $545^{d}$ & $22.7^{d}$ \\
DHL Airways (logistics) & $04 / 2004$ & Germany (Leipzig) & 70 & 28.0 \\
Peugeot Citroen & $09 / 2004$ & U.K. (Ryton) & 30 & 9.8 \\
\hline
\end{tabular}

${ }^{a}$ automobiles, unless otherwise stated $\quad{ }^{b} 1$ British Pound is converted to $1.5 €$

${ }^{c}$ present value of state aid divided by present value of investment $\quad{ }^{d}$ upper limit

Source: Official Journal of the European Communities, C and L (http://eur-lex.europa.eu)

In the present paper we take an integrated view of these simultaneous developments. If investment subsidies and corporate tax payments are viewed together and compared in present-value terms, in many cases it is not clear whether firms actually make net tax payments to their host countries or if, instead, governments pay mobile firms to locate within their jurisdictions. Therefore one of the main goals of our analysis is to identify the conditions in equilibrium under which payments flow from firms to countries and when the reverse occurs. We do so in a model that incorporates a desire on the part of national governments to attract internationally mobile firms, but also gives governments the ability to tax the location rents earned by firms.

More specifically, we set up a model of generalised oligopoly where two countries comTable 1) for a similar collection of investment subsidies granted by the U.S. states. 
pete for an exogenous, but variable, number of identical firms. Governments want to attract firms to their jurisdiction in order to save on trade costs and thereby reduce consumer prices. This gives them an incentive to offer subsidies to mobile firms. At the same time, there are location rents for the firms. These arise because any firm that moves from one country to the other will face a different number of firms in its new location, and the changed competitive environment will affect its profits. There is a positive location rent if such a firm would suffer a fall in profits from moving out of its current location and the host government has an opportunity to grab this rent through taxes. Whether taxes are positive or negative in the location equilibrium depends on the interplay of these two forces. Our model is simple enough to allow us to derive reduced-form expressions for the equilibrium tax rates on mobile firms, even in the case where countries are of asymmetric size. A core question raised in our analysis is how economic integration (a fall in trade costs) affects tax rates and welfare in the large and in the small country. We find that equilibrium tax rates in both countries are positive at high levels of trade costs, then fall to negative values (i.e. location subsidies) as economic integration proceeds, and finally rise again when trade costs fall even further. Similarly welfare levels are first falling and then rising again when trade costs are continuously reduced. Importantly, there is a range of trade costs where economic integration raises the welfare of the small country, but lowers welfare in the large country.

Our model is related to two strands in the literature that have so far developed independently, and have led to rather different conclusions. A first set of papers focuses on the competition of potential host countries for a single multinational firm. In these models the equilibrium policy generally involves a location subsidy to the firm. Reasons why countries (or states) will want to attract firms include: scale economies in the provision of public goods and services, in conjunction with a mobile workforce (Black and Hoyt, 1989); positive spillovers from employment in the host jurisdiction (Haaparanta, 1996; Davies, 2005); savings in trade costs (Haufler and Wooton, 1999); or technological backwardness (Fumagalli, 2003). Recent work has shown, however, that these results change when an indigenous firm is already operating in one of the countries (Bjorvatn and Eckel, 2006) or when countries compete for two mobile firms, rather than one (Ferrett and Wooton, 2005). In the latter case countries may even be 
able to tax away all profits in the non-cooperative tax equilibrium. A general feature of these models is that they involve the comparison of discrete equilibrium allocations and analyse specific scenarios that are difficult to compare or generalise.

A second literature strand has analysed tax competition for internationally mobile firms in models of the new economic geography (Kind et al., 2000; Baldwin and Krugman, 2004; Ottaviano and van Ypersele, 2005; Borck and Pflüger, 2006). These models employ a framework of monopolistic competition where otherwise identical firms produce different varieties of a composite good. ${ }^{3}$ This literature has stressed that agglomeration rents can be taxed, at positive levels, by the government of a 'core country'. However, this result applies only in the special case where all firms are agglomerated in one country, whereas subsidies are paid in equilibrium when firms are regionally dispersed. In contrast the present model focuses only on interior location equilibria and shows that positive tax rates can arise even if firms are fully dispersed in equilibrium.

Our analysis develops as follows. In section 2 we present the basic model. Section 3 analyses the non-cooperative tax equilibrium and the allocation of firms in the case where countries are symmetric and in the case where they differ in size. Section 4 analyses the welfare effects of economic integration, again differentiating between the scenarios of symmetric and of asymmetric countries. In section 5 we analyse the robustness of our results by incorporating profit income and an excess burden of taxation into the objective function of national governments. Section 6 discusses the results and relates them to the existing literature. Section 7 concludes.

\section{The model}

\subsection{Consumers}

We consider a region with two countries $a$ and $b$, which compete to attract a fixed number of firms. These firms produce an homogeneous good, labelled $x$, in an oligopolistic industry. A second, private good, the numeraire commodity $z$, is produced under con-

\footnotetext{
${ }^{3}$ For an extension that accounts for firm heterogeneity, see Burbidge et al. (2006). Another related analysis is Fuest (2005) who studies the implications for tax policy when economic integration reduces trade barriers but also increases the foreign ownership share of domestic firms.
} 
ditions of perfect competition. Consumers in both countries have identical preferences for the goods, given by

$$
u_{i}=\alpha x_{i}-\frac{\beta}{2} x_{h}^{2}+z, \quad i \in\{a, b\} .
$$

The two countries potentially differ in size. The population of the region is normalised to unity and, without loss of generality, we take country $a$ to be the larger of the two. Let there be $n \geq 0.5$ consumers in country $a$ and $(1-n)$ consumers in country $b$. In most of our analysis, the residents of countries $a$ and $b$ earn only wage income, while profit income accrues to capital owners that reside in a third (outside) country. ${ }^{4}$ Every household in the region supplies a single unit of labour. The wage rate in each country is determined in the numeraire industry, which uses labour as the only input. Free trade in the numeraire good therefore equalises the wage across the countries as $w$. Moreover, total income from the business tax (as detailed below), denoted by $T_{i}$, is redistributed equally and in a lump-sum fashion to the consumers in each country. The budget constraint for a representative consumer in each of the two countries is then

$$
w+\frac{T_{a}}{n}=z+p_{a} x_{a}, \quad w+\frac{T_{b}}{1-n}=z+p_{b} x_{b},
$$

where $p_{i}$ is the price of good $x$ in country $i$. Utility maximisation leads to the inversedemand curves

$$
\alpha-\beta x_{i}=p_{i}, \quad i \in\{a, b\} .
$$

Aggregating the demand for good $x$ over all consumers yields market demand curves for each country, denoted $X_{i}$

$$
X_{a}=\frac{n\left(\alpha-p_{a}\right)}{\beta}, \quad X_{b}=\frac{(1-n)\left(\alpha-p_{b}\right)}{\beta} .
$$

When $n>0.5$, the market demand curve of the larger country $a$ is flatter than that of country $b$. In this sense market $a$ is the more profitable one for firms, as we will see below.

\section{$2.2 \quad$ Firms}

Each firm in the imperfectly competitive industry $x$ requires one unit of capital to produce any output. There is a total of $k$ units of capital in the world economy, implying

\footnotetext{
${ }^{4}$ In section 5 we will consider the more general case where all profit income accrues to the residents of countries $a$ and $b$.
} 
that a maximum of $k$ firms can engage in production. ${ }^{5}$ There are fixed and identical costs of setting up operations in each of the two countries. This ensures that each firm will locate in only one country, if it enters the region at all. ${ }^{6}$ The firms are assumed to be identical except with respect to the location of their production facilities. Location matters because, while all firms can sell their products in both countries, there are trade costs associated with exports to a firm's foreign market. Thus each country may be served by both "local" firms that produce domestically and "foreign" firms that are based in the other country.

We assume that labour is the only variable input. Each unit of output requires the efforts of a single worker and hence the marginal cost is $w .^{7}$ The cost of exporting each unit of output is $\tau$, which effectively raises the marginal cost of serving the foreign market to $(w+\tau)$. Firms are assumed to behave as Cournot competitors and are able to segment their markets, choosing the quantities to sell on their domestic and export markets independently. ${ }^{8}$

Capital owners choose output levels in each market in order to maximise the total profit of each firm (which equals the return to capital) :

$$
\begin{aligned}
& \pi_{a}=\left(p_{a}-w\right) x_{a a}+\left(p_{b}-w-\tau\right) x_{b a}, \\
& \pi_{b}=\left(p_{a}-w-\tau\right) x_{a b}+\left(p_{b}-w\right) x_{b b}
\end{aligned}
$$

where $\pi_{j}$ is the pre-tax profit of a firm based in country $j$ and $x_{i j}$ represents sales in country $i$ by a firm based in country $j(i, j \in\{a, b\})$. Given that the marginal cost of exports is relatively higher than that for domestic sales, a firm's perceived marginal revenue in its export market must be comparably larger. In equilibrium, this will arise

\footnotetext{
${ }^{5}$ Our model treats $k$ as a continuous variable. Hence the analysis only approximates the "true" model when the number of firms is small and the relocation of a single firm has discrete implications for the equilibrium allocation. This will be further discussed in section 6 . The main advantage of this procedure is that we can derive equilibrium allocations and policies as continuous functions of exogenous model parameters.

${ }^{6}$ For notational simplicity these fixed costs are suppressed in the equations below.

${ }^{7}$ Since wage costs are equalised between the two countries, they do not enter the location decision of firms in our model. For a recent analysis of tax competition for foreign direct investment which focuses on production cost differentials, see Davies (2005).

${ }^{8}$ In equilibrium, firms will receive a lower producer price for their exports than for goods destined for the domestic market. The trade structure is simply a generalisation of the "reciprocal dumping" model of Brander and Krugman (1983).
} 
when each foreign firm has a relatively smaller market share than that of a domestic firm (as perceived marginal revenue is inversely related to market share). Essentially, a firm is at a cost disadvantage in its export markets and will sell less than an indigenous rival.

Suppose that $m$ firms are located in country $a$ and the remaining $(k-m)$ firms produce in country $b$. Maximising (5) taking into account demand (4), yields firm output levels:

$$
\begin{array}{ll}
x_{a a}=\frac{n[\alpha-w+(k-m) \tau]}{\beta(k+1)} ; & x_{b a}=\frac{(1-n)[\alpha-w-(1+k-m) \tau]}{\beta(k+1)} ; \\
x_{a b}=\frac{n[\alpha-w-(1+m) \tau]}{\beta(k+1)} ; & x_{b b}=\frac{(1-n)[\alpha-w+m \tau]}{\beta(k+1)} .
\end{array}
$$

Note that $x_{a b} / x_{a a}, x_{b a} / x_{b b}<1$, confirming our assertion that a foreign firm's share of a market is always less than that of a local firm whenever there are trade costs $(\tau>0) .{ }^{9}$ The corresponding equilibrium market outputs and prices are:

$$
\begin{array}{ll}
X_{a}=\frac{n[k(\alpha-w)-(k-m) \tau]}{\beta(k+1)} ; & X_{b}=\frac{(1-n)[k(\alpha-w)-m \tau]}{\beta(k+1)} ; \\
p_{a}=\frac{\alpha+k w+(k-m) \tau}{k+1} ; & p_{b}=\frac{\alpha+k w+m \tau}{k+1} .
\end{array}
$$

Notice that consumer prices in both countries fall when the total number of firms $k$ increases and competition in the oligopolistic industry is thereby intensified. Moreover, for any given level of $k$, increasing $m$ (the number of firms that locate in country $a$ ) reduces the consumer price of good $x$ in that country, but increases the price in country $b$. That is, whatever the size of the industry, having more firms producing locally intensifies domestic competition and drives down consumer prices.

Substituting (6) and (7) into (5) yields the pre-tax profits of firms located in each country:

$$
\begin{aligned}
& \pi_{a}=\frac{n[\alpha-w+(k-m) \tau]^{2}}{\beta(k+1)^{2}}+\frac{(1-n)[\alpha-w-(1+k-m) \tau]^{2}}{\beta(k+1)^{2}} \\
& \pi_{b}=\frac{n[\alpha-w-(1+m) \tau]^{2}}{\beta(k+1)^{2}}+\frac{(1-n)[\alpha-w+m \tau]^{2}}{\beta(k+1)^{2}} .
\end{aligned}
$$

\footnotetext{
${ }^{9}$ As our model allows for differences in country size, this is not inconsistent with the possibility that a firm may sell more in its export market than at home.
} 
We assume that profits are taxed at source by the host countries of the firms. ${ }^{10}$ Let $t_{i}$ be the lump-sum tax imposed on each firm by country $i$. Thus total tax revenues are

$$
\begin{array}{rll}
T_{a}=t_{a} m & \text { for country } a & \text { and } \\
T_{b}=t_{b}(k-m) & \text { for country } b .
\end{array}
$$

The tax differential between countries is $\Delta \equiv t_{a}-t_{b}$. In deciding upon where to invest, firms will compare profits net of taxes and locate in the more profitable country. The locational equilibrium for the industry will be characterised by $\pi_{a}-t_{a}=\pi_{b}-t_{b}$. Substituting (8) gives the equilibrium number of firms choosing to locate in country $a$ :

$$
m=\frac{k}{2}+\frac{(2 n-1)[2(\alpha-w)-\tau]}{2 \tau}-\frac{\Delta \beta(k+1)}{2 \tau^{2}} .
$$

Suppose, initially, that each country charges the same tax, that is $\Delta=0$. If the countries were the same size $(n=0.5)$, it is clear from (10) that $m=k / 2$, that is, the firms would be evenly split between the two locations. In the absence of trade costs, neither country has a locational advantage and $m$ is undefined. When trade is costly and country $a$ is relatively large $(n>0.5)$, it attracts more than half of the firms. Differences in taxes will further affect the location of firms such that, if country $a$ taxes firms more heavily than country $b$ (that is, $\Delta>0$ ), $a$ 's share of the firms will be relatively smaller than it would otherwise be.

How is the international distribution of firms affected by changes in relative country size, trade costs, and tax differences? Partial differentiation of (10) yields:

$$
\begin{aligned}
& \frac{d m}{d n}=\frac{2(\alpha-w)-\tau}{\tau}>0 ; \\
& \frac{d m}{d \tau}=\frac{-(2 n-1)(\alpha-w)}{\tau^{2}}+\frac{\Delta \beta(k+1)}{\tau^{3}} \lessgtr 0 ; \\
& \frac{d m}{d \Delta}=\frac{d m}{d t_{a}}=\frac{-\beta(k+1)}{2 \tau^{2}}=-\frac{d m}{d t_{b}}<0 .
\end{aligned}
$$

We see from (11) that, as the asymmetry in country size $(n)$ increases, country $a$ attracts a greater share of the firms while the effect of rising trade costs on firm location

\footnotetext{
${ }^{10}$ There is a general agreement in the literature that international company taxation closely follows the source principle. This principle applies directly, if countries avoid international double taxation by exempting foreign-earned income from domestic tax. If countries grant an international tax credit instead, source taxation is still effective in many cases, because crediting applies only after profits have been repatriated and because countries do not rebate 'excess' taxes paid abroad.
} 
is ambiguous. Whenever $a$ is larger than $b$ (i.e., that is $n>0.5$ ) the direct (first) effect of a rise in trade costs is to increase the international dispersion of firms, moving more firms to the smaller country. However, higher trade costs also imply that the impact of a given international tax differential becomes less important. If the large country levies the higher $\operatorname{tax}(\Delta>0)$, this isolated (second) effect works in the direction of increasing the number of firms in country $a$. Hence the net effect of changes in trade costs on the concentration of industry will only be determined once tax rates are endogenised in section 3.2. Lastly, increasing a country's tax clearly creates a disincentive for firms to locate there.

\subsection{Governments}

The governments of countries $a$ and $b$ each impose lump-sum taxes on firms that locate within their respective jurisdictions. Importantly, these taxes can be negative, acting as subsidies to attract investment to a particular country. If revenues from the business tax are positive, then these are redistributed equally and in a lump-sum way to the residents in the country in which they are collected. The costs of a negative business tax are raised through lump-sum taxation of consumers. Recall that, despite their lump-sum character, business taxes still distort the location decision of internationally mobile firms [eq. (10)]. ${ }^{11}$

In addition to tax revenue, governments care about the consumer surplus of households in their jurisdictions. Substituting the equilibrium market prices for good $x$ [see (7)] into the linear market demand curves (4), total consumer surplus, denoted $S_{i}$, in each of the two countries is given by

$$
S_{a}=\frac{n[k(\alpha-w)-(k-m) \tau]^{2}}{2 \beta(k+1)^{2}}, \quad S_{b}=\frac{(1-n)[k(\alpha-w)-m \tau]^{2}}{2 \beta(k+1)^{2}} .
$$

It is straightforward to show that consumer surplus in both countries is rising in the total number of firms $k$, as this intensifies competition and reduces producer prices in both countries [cf. eq. (7)]. Moreover, a rise in $m$, the share of firms located in country $a$,

\footnotetext{
${ }^{11}$ Introducing an ad valorem profit tax instead of a unit lump-sum tax on firms would complicate the algebra, but it would cause no further distortions and hence would not change any of our qualitative results. The assumption that lump-sum taxes are available to cover the costs of subsidies to firms will be relaxed in section 5 .
} 
raises consumer surplus in that country, but lowers it in country $b$, because, as we have already established, consumer prices are lower when more firms produce locally. This gives each nation an incentive to attract firms to its home jurisdiction. ${ }^{12}$

We initially assume that firms' profits accrue to the residents of a third country (but recall footnote 4 ). The objective of each government is then simply to maximise the sum of consumer surplus and tax revenue collected from locally producing firms. Consequently, the objective functions of the two governments are

$$
W_{a}=S_{a}+T_{a}, \quad W_{b}=S_{b}+T_{b}
$$

We substitute (9) and (12) in (13) and differentiate each country's welfare expression with respect to its own tax, using the derivative properties of $m$ in (11). This gives the following first-order conditions for each country's tax rate:

$$
\begin{aligned}
t_{a} & =\frac{\tau\{\tau m[2(k+1)-n]-n k(\alpha-w-\tau)\}}{(k+1)^{2} \beta} ; \\
t_{b} & =\frac{\tau\{\tau(k-m)[2(k+1)-(1-n)]-k(\alpha-w-\tau)\}}{(k+1)^{2} \beta} .
\end{aligned}
$$

These expressions still include $m$, which is endogenous. To arrive at reduced-form expressions for the Nash equilibrium tax rates, eq. (10) must be substituted into the set of first-order conditions (14). To develop an intuition for our results we will first perform this analysis in the benchmark case of symmetric countries. In a second step, we progress to the more general case where countries differ in size.

\section{Equilibrium taxes and location}

\subsection{Benchmark: Symmetric countries}

To analyse the benchmark case where countries are identical in all respects, we evaluate the first-order conditions for the two countries' optimal tax rates (14) at $n=0.5$ and

\footnotetext{
${ }^{12}$ Clearly, savings in transportation cost are only one (analytically convenient) example of why governments may want to attract internationally mobile firms. This motive could, for example, be replaced by technological linkages that exist between the oligopolistic industry $x$ and the production of the numeraire good $z$. Such a setting would yield similar qualitative conclusions, but would involve a more complex analysis.
} 
substitute the equilibrium allocation of firms (10), again using this restriction. This yields best-response functions where each country's tax is a function of the tax set by the other nation's government:

$$
t_{i}\left(t_{j}\right)=\frac{k \tau\{4 \tau(k+1)-[2(\alpha-w)-\tau]\}}{(k+1) \beta[8(k+1)-1]}+t_{j} \frac{[4(k+1)-1]}{[8(k+1)-1]}, i, j \in\{a, b\}, i \neq j .
$$

These symmetric, best-response functions have positive slopes, implying that an increase in one country's business tax rate will raise that of the other country.

Solving the pair of simultaneous equations yields closed-form solutions for the common Nash equilibrium tax rate:

$$
t^{s}=\frac{k \tau}{(k+1) \beta}\left[\tau-\frac{2(\alpha-w)-\tau}{4(k+1)}\right]
$$

where the superscript $s$ stands for the symmetric case. These equilibrium tax rates (16) reflect two fundamental effects that are at work in the present model.

The positive first term in the square brackets arises from a competition effect. Intuitively, starting from a symmetric equilibrium and moving one firm from country $b$ to country $a$ implies that each firm in country $a$ now faces more intense competition in its home market. Since a firm's home market is relatively more profitable than its export market, the gross profits of each firm in country a fall, whereas the gross profits of each firm that remains in country $b$ rise. This profit differential implies that a location rent arises for each firm even in a fully symmetric equilibrium, in the sense that the next best alternative (i.e., relocation to the other country) involves lower gross profits. This location rent can be taxed by the host government without causing a firm to move to the other jurisdiction. ${ }^{13}$ This competition effect becomes stronger with higher trade costs, as these increase the difference in profitability between the home and the foreign markets.

In contrast, the second term in the square brackets of (16) is the source of a negative, consumer-price effect. When an additional firm enters a country, consumer prices fall and, as discussed above, this provides each country with an incentive to offer location subsidies to firms.

\footnotetext{
${ }^{13}$ Algebraically, this effect can be shown by differentiating the gross profits that each firm earns in a symmetric equilibrium [eq. (8)] with respect to $m$. The resulting profit differential between a firm that is located in country $b$ and one that is located in $a$ is just equal to the first term in (16).
} 
From (16) we can determine the critical level of trade $\operatorname{costs} \tau^{*}$ at which the two effects just offset one another such that equilibrium taxes are zero:

$$
\tau^{*}=\frac{2(\alpha-w)}{4(k+1)+1}
$$

For trade costs $\tau>\tau^{*}$ the competition effect dominates and equilibrium tax rates are positive, whereas for $\tau<\tau^{*}$ the consumer price effect is relatively stronger and equilibrium taxes are negative (that is, subsidies are given). Finally, neither effect has any impact in the absence of trade costs $(\tau=0)$. In this free-trade case, the Nash equilibrium taxes are zero as both governments and firms are indifferent to the equilibrium pattern of firm location. ${ }^{14}$

It should be noted that governments are constrained in their ability to tax, as posttax profits must remain non-negative for all $k$ firms. Otherwise some of the firms would choose not to produce. To derive this constraint, we subtract the tax rate in the symmetric Nash equilibrium (16) from a firm's pre-tax profits (8). Setting the difference equal to zero yields a critical value of trade costs $\bar{\tau}$ where:

$$
\bar{\tau}=\frac{(\alpha-w)\left[k-2+\sqrt{13 k^{2}+8 k-4}\right]}{\left(3 k^{2}+3 k-2\right)} .
$$

Equation (18) defines a negative relationship between the total number of firms in the market and the critical (maximum) level of trade costs $\bar{\tau}$. Only if $\tau \leq \bar{\tau}$, will all $k$ firms be prepared to enter and produce in the region. For any given level of $(\alpha-w)$, a high $k$ reduces the gross profits that can be earned by each firm in equilibrium. In contrast, a high level of $\tau$ increases the ability of a country to set higher taxes when these taxes are positive in the initial equilibrium. ${ }^{15}$

We can also derive a condition under which positive levels of trade will occur in equilibrium. In the symmetry of the benchmark case, this condition is the same for firms located in either country. From (8) and using $m=k / 2$, we find that exporting to

\footnotetext{
${ }^{14}$ This special case is related to the analysis by Janeba (1998), who introduces firm mobility to the standard model of strategic tax policy but does not include transport costs. He shows that equilibrium trade taxes will then be zero in both countries, in contrast to the trade subsidies that result in the absence of firm mobility (and with Cournot competition of firms).

${ }^{15}$ It is easily checked that the critical level of $\tau$ at which equilibrium tax rates turn positive [eq. (17)] is below $\bar{\tau}$ and hence there is indeed a range of transport costs for which positive equilibrium taxes result. This is, of course, a consequence of firms earning positive gross profits in our model.
} 
the other market is profitable as long as trade costs are less than prohibitive, that is, $\tau<\tau^{P}$, where the prohibitive trade cost is

$$
\tau^{P}=\frac{2(\alpha-w)}{2+k}
$$

If $\tau>\tau^{P}$, there will be no trade. Consequently, there will be $k / 2$ firms selling in each autarkic market in equilibrium. Comparing the critical values in (18) and (19) shows that $\bar{\tau} \leq \tau^{P}$ for all $k \geq 2$. Hence eq. (18) is the binding constraint in our model. When this constraint is met and all $k$ firms make non-negative after-tax profits, then there will also be international trade in equilibrium.

How are the symmetric Nash equilibrium tax rates affected by changes in the exogenous parameters of the model? Consider first an increase in the total number of mobile firms in the economy. Differentiating (16) with respect to $k$ yields

$$
\frac{\partial t^{s}}{\partial k}=\frac{\tau\{4 \tau(k+1)+(k-1)[2(\alpha-w)-\tau]\}}{4(k+1)^{3} \beta}>0 .
$$

An increase in $k$ unambiguously raises equilibrium tax rates. Intuitively, a rise in the total number of firms lowers the costs that are perceived by each country from losing one of the firms to the other country. The decline in the consumer-price effect reduces the willingness of each country to grant location subsidies. Moreover the larger number of firms strengthens the positive competition effect. This aspect can be explained as follows. The stronger is competition, and hence the closer prices are to marginal costs, the more severe is the disadvantage from having to bear extra trade costs. This is seen from the model property that the market share of foreign firms falls when the total number of firms is increased [cf. eq. (6)]. Hence, starting from a symmetric equilibrium, the penalty rises for a firm that attempts to escape high domestic taxes by moving abroad, and this strengthens the ability of each country to tax location rents. ${ }^{16}$ Increasing the market size of both countries (a rise in $\alpha$ ) has the opposite implications. In this case it is directly inferred from (16) that $\partial t^{s} / \partial \alpha<0$. With higher sales per firm, each country has more to gain from attracting an additional firm so that the

\footnotetext{
${ }^{16}$ This effect underlies the different results in models where two countries compete for a single monopolist and pay subsidies in equilibrium, and those where they compete for two mobile firms and are able to levy positive taxes (see Ferrett and Wooton, 2005). Our analysis show that this effect holds more generally, and also applies to continuous increases in the number of firms.
} 
Figure 1: Nash equilibrium tax rates in the symmetric equilibrium

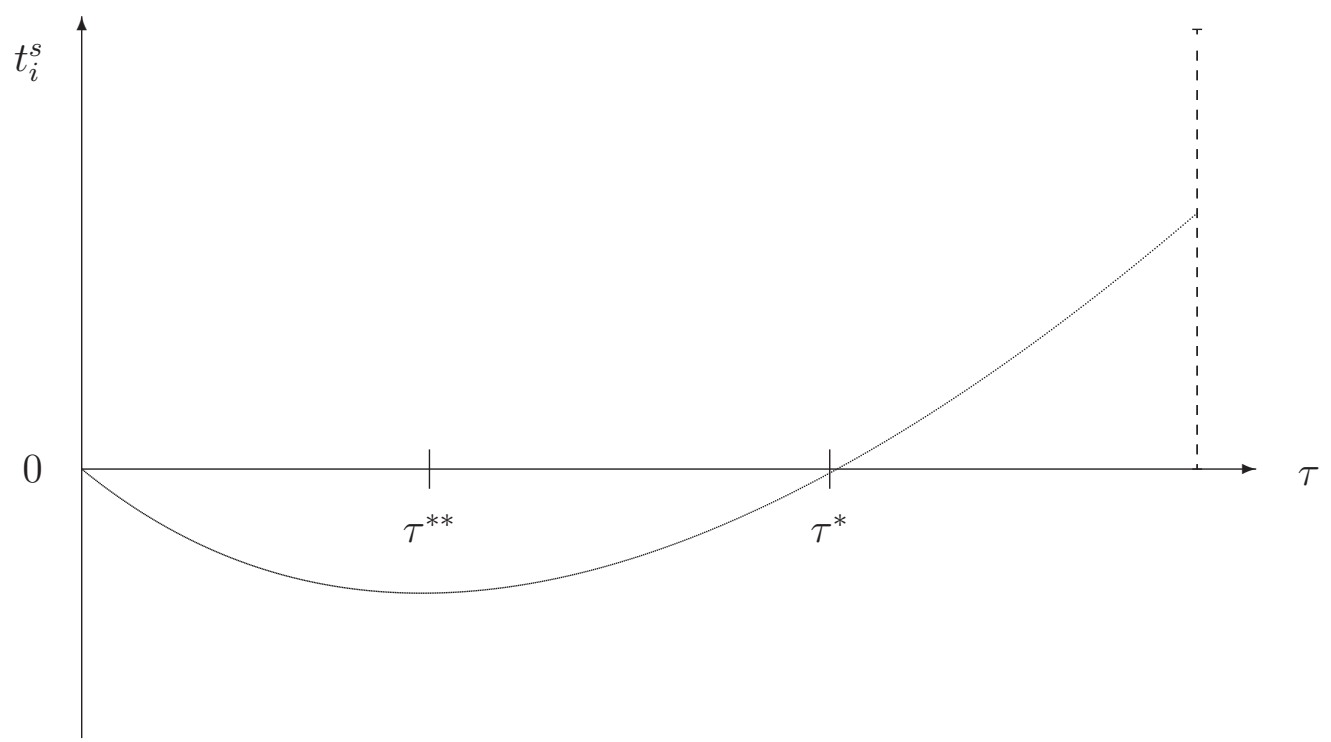

consumer-price effect becomes larger. On the other hand, the competition effect is not affected by an increase in the size of both markets. Hence each country will find it optimal to lower its profit tax, even though sales and gross profits per firm rise. This shows very clearly that there is no link in our model between equilibrium tax rates and the gross profits earned by each firm. What matters instead is only the countries' bargaining position vis-à-vis each mobile firm.

Finally, we turn to changes in trade costs. Differentiating (16) with respect to $\tau$ gives

$$
\frac{\partial t^{s}}{\partial \tau}=\frac{k[4 \tau(k+1)-(\alpha-w-\tau)]}{2(k+1)^{2} \beta},
$$

which may be positive or negative. However, we can determine a critical threshold value for $\tau$, for which this derivative is zero. This is

$$
\tau^{* *}=\frac{\alpha-w}{4(k+1)+1} .
$$

For $\tau>\tau^{* *}$, the tax rate is rising in trade costs, whereas for $\tau<\tau^{* *}$ it is falling in $\tau$. Moreover, comparing (21) with (17) shows that $\tau^{* *}<\tau^{*} / 2$.

The relationship between the level of trade costs and the equilibrium tax rates in the symmetric Nash equilibrium is then as shown in Figure 1. This figure shows that, starting from high levels of trade costs $\left(\tau>\tau^{*}\right)$, a fall in these costs (commonly interpreted as economic integration) will reduce the ability of symmetric countries 
to raise positive business taxes. Below $\tau^{*}$ taxes turn negative and continue to fall until they reach a minimum (i.e., a maximum subsidy) at $\tau^{* *}$. To explain this negative relationship for relatively high levels of trade costs, note that the competition effect and the consumer price effect are both weakened when trade costs are reduced. However, the ability of countries to extract location rents falls more quickly as long as $\tau>\tau^{* *}$. If trade costs fall still further $\left(\tau<\tau^{* *}\right)$, the relative strength of the competition and consumer price effects is reversed and tax rates rise again until they reach zero at $\tau=0$.

Our results are summarised in

Proposition 1 If both countries are identical, symmetric equilibrium tax rates are falling in market size and rising in the number of mobile firms. As economic integration proceeds (trade costs fall), equilibrium tax rates first fall and then rise again. There is a critical value of trade costs $\tau^{*}$, where equilibrium taxes switch from positive to negative (i.e., to subsidies).

\subsection{Differences in country size}

Having discussed the basic working of our model in the special case of symmetry, we now turn to the more general case where countries differ in size. Substituting $m$ from (10) into (14) we obtain closed-form solutions for the asymmetric Nash equilibrium tax rates:

$$
\begin{aligned}
& t_{a}^{*}=\frac{k \tau}{\beta(k+1)}\left[\tau-\frac{n \mu}{2(k+1)}\right]+\frac{\tau \mu(2 n-1)(3 k+2)[2(k+1)-n]}{2 \beta(k+1)^{2}[6(k+1)-1]}, \\
& t_{b}^{*}=\frac{k \tau}{\beta(k+1)}\left[\tau-\frac{n \mu}{2(k+1)}\right]-\frac{\tau \mu(2 n-1)[2(k+1)+n(3 k+2)]}{2 \beta(k+1)^{2}[6(k+1)-1]},
\end{aligned}
$$

where $\mu \equiv[2(\alpha-w)-\tau]>0$. The derivations of $(22)$ are relegated to the appendix. The first term in (22) is identical for both countries and captures the counteracting competition and consumer-price effects that have been discussed above. ${ }^{17}$ The second terms in (22) show how the overall bargaining position of countries vis-à-vis individual firms is modified by an additional home-market effect. Each firm will save aggregate trade costs and thereby make higher gross profits when it locates in the larger country. This allows the larger country $a$ to impose a higher tax than in the symmetric

\footnotetext{
${ }^{17}$ It is easily checked that the first terms in (22) reduce to eq. (16) for the symmetric case $n=0.5$.
} 
equilibrium, whereas the smaller country $b$ has to compensate firms for its location disadvantage by offering a lower tax (or a higher subsidy). The equilibrium tax differential is given by

$$
\Delta^{*} \equiv t_{a}^{*}-t_{b}^{*}=\frac{3 \tau(2 n-1)[2(\alpha-w)-\tau]}{\beta[6(k+1)-1]}>0 .
$$

This differential increases as the disparity in country size $n$ becomes greater and as the size of the market $\alpha$ expands, but it falls as the total number of firms in the industry $k$ increases.

The home-market effect is strengthened by high trade costs, as is seen from differentiating (23) with respect to $\tau$ :

$$
\frac{\partial \Delta^{*}}{\partial \tau}=\frac{6(2 n-1)(\alpha-w-\tau)}{\beta[6(k+1)-1]}>0 .
$$

This derivative is unambiguously positive when international trade occurs [cf. (19)]. Economic integration, in the form of a decline in trade costs, will reduce the absolute tax differential between the large and the small country.

Looking more closely at the effects of changes in trade costs, differentiating the tax levels in each country [eq. (22)] and re-substituting their values in the initial equilibrium yields:

$$
\frac{\partial t_{i}^{*}}{\partial \tau}=\frac{2\left[(\alpha-w-\tau) t_{i}^{*}+(\alpha-w)\right]}{\tau[2(\alpha-w)-\tau]} \quad \forall i \in\{a, b\} .
$$

Hence, for either of the two countries, a positive tax rate in the initial equilibrium is sufficient (but not necessary) to ensure that a fall in trade costs reduces the optimal tax rate. This result parallels that for symmetric countries. However, from (22), the critical level of trade costs at which the large country's tax rate turns positive is now reduced, relative to the symmetric case, whereas the critical level of trade costs at which the small country is able to levy positive taxes is increased.

Next we turn to the equilibrium pattern of firm location. This is determined by substituting the optimal tax rates in (22) into equation (10), yielding

$$
m=\frac{k}{2}+\frac{(2 n-1)[2(\alpha-w)-\tau]}{2 \tau} \frac{[3(k+1)-1]}{[6(k+1)-1]} .
$$

Equation (26) implies that a threshold level of trade costs, denoted $\underline{\tau}$, must be exceeded in order to meet the restriction that the number of firms in the small country $b$ is 
Figure 2: Nash equilibrium taxes in the asymmetric equilibrium

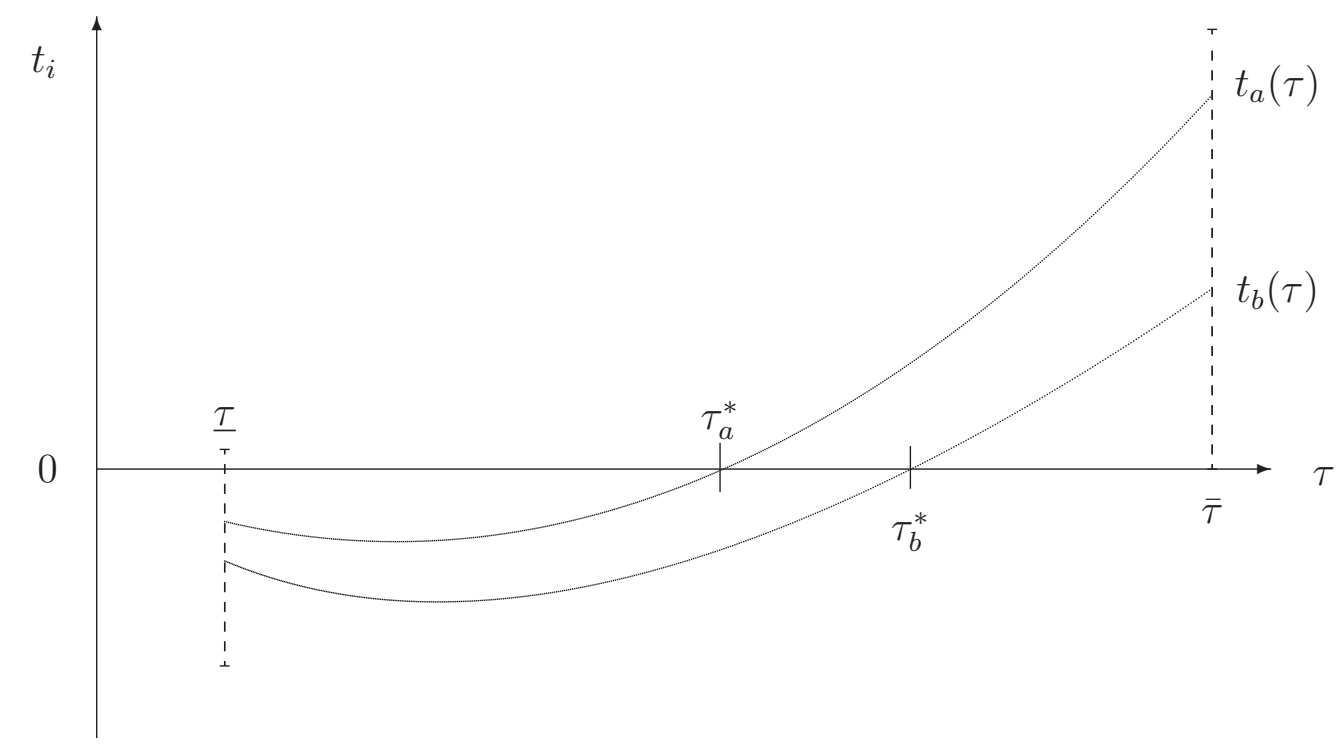

positive $(m<k)$. This lower bound for $\tau$ in the presence of size asymmetries is given by

$$
\underline{\tau}=\frac{2(\alpha-w)(2 n-1)[3(k+1)-1]}{k[6(k+1)-1]+(2 n-1)[3(k+1)-1]} .
$$

The lower bound $\tau$ is zero in the case of symmetric countries and it rises as the size differential between countries $a$ and $b$ increases. In other words, if low levels of trade costs (and thus a high degree of economic integration) are to be considered in our model, then the size asymmetries between the two countries must not be "too large". The relationship between trade costs and equilibrium tax rates in each of the two countries is then as shown in Figure 2. ${ }^{18}$

We have already established that the number of firms that locates in the larger of the two countries (country $a$ ) is rising in the size difference $n$. However, the effects of trade costs on the equilibrium location of firms are ambiguous, in general, when the level of tax rates is exogenous [see (11)]. We can now evaluate the comparative static effect of a change in $\tau$ at the asymmetric tax equilibrium. Differentiating (26) with respect to

\footnotetext{
${ }^{18}$ To simplify the graph, Figure 2 ignores the fact that the maximum levels of trade costs that are compatible with non-negative profits $(\bar{\tau})$ will generally differ for the two countries. The countryspecific levels of $\bar{\tau}$ are computed by substituting (26) in (8) and setting the resulting gross profit levels equal to the lump-sum taxes (22).
} 
$\tau$, and noting that $(1-2 n)<0$, yields:

$$
\frac{\partial m}{\partial \tau}=\frac{(1-2 n)[3(k+1)-1]}{2 \tau[6(k+1)-1]}\left\{1+\frac{[2(\alpha-w)-\tau]}{\tau}\right\}<0 .
$$

Hence a fall in trade costs will unambiguously increase the number of firms in the larger country $a$. The dominant effect is that trade costs shield the firms that locate in one market from the competition of firms that have located in the other. As trade costs fall, the competitive pressure rises relatively more in the small country $b$, because a larger number of firms (those located in $a$ ) become closer competitors. Hence market integration makes it less attractive to locate in the small country, resulting in an increase in the concentration of production activity. These results are summarised in

Proposition 2 When countries differ only in size, the country with the larger home market imposes the higher tax rate. A fall in trade costs lowers the equilibrium tax differential and increases the concentration of firms in the larger country.

\section{Economic integration and national welfare}

We now turn to the welfare effects of economic integration and start again with the benchmark case of symmetric countries. Substituting (12) and (16) in (13) and setting $m=k / 2$ yields the maximised welfare for each country

$$
W^{s}=\frac{k^{2}}{16 \beta(k+1)^{2}}\left\{[2(\alpha-w)-\tau]^{2}+2 \tau^{2}[4(k+1)+1]-4 \tau(\alpha-w)\right\} .
$$

Differentiating with respect to $\tau$ yields

$$
\frac{\partial W^{s}}{\partial \tau}=\frac{k^{2}}{16 \beta(k+1)^{2}}\{[8(k+1)+3] \tau-4(\alpha-w)\} .
$$

For high levels of trade costs, economic integration (a fall in $\tau$ ) is welfare-reducing for both countries while for low trade costs, a further reduction is instead welfareincreasing. The critical value of trade costs, where welfare reaches a minimum is obtained by setting $\partial W^{s} / \partial \tau$ in (29) equal to zero. This critical value $\tilde{\tau}$ is:

$$
\tilde{\tau}=\frac{4(\alpha-w)}{[8(k+1)+3]} .
$$

This $U$-shaped relationship between national welfare and trade costs closely mirrors the relationship between equilibrium tax rates and trade costs. At high levels of trade costs, 
a reduction in these costs weakens the competition effect, reducing the tax power of governments in the symmetric equilibrium, and lowering both tax revenue and welfare. At low levels of $\tau$, a further fall in trade costs reduces the gains for each country from granting location subsidies to firms. This alleviates subsidy competition and increases each country's welfare. Comparing the critical level $\tilde{\tau}$ to the level of trade costs that induces the minimum tax $\tau^{* *}$ [see eq. (21)], shows that $\tilde{\tau}>\tau^{* *}$. Thus, as trade costs fall below $\tilde{\tau}$, tax rates continue to decline for some range of trade costs to the left of $\tilde{\tau}$ while welfare starts to climb again. The increase in welfare is explained by the fact that the falling tax revenues (alternatively, the increasing subsidy payments) are more than compensated by the rise in consumer surplus associated with the reduction in trade costs.

To analyse the effects on national welfare when countries differ in size, we substitute (10), (12) and (22) in (13). At low levels of economic integration equilibrium taxes are positive in both countries and a reduction in $\tau$ will cause taxes and welfare to fall. However the welfare-minimizing levels of $\tau$ will differ for the large and the small country. Given that welfare in each country is a non-monotonic function of trade costs, there is the possibility that economic integration will have the opposite welfare effect in each country over a certain range of $\tau$. In particular, it can be shown that this is the case when the trade cost is equal to $\tilde{\tau}$, as defined in (30). At this level of trade costs (and, from continuity, in the neighbourhood of this value), the following holds:

$$
\left.\frac{\partial W_{a}}{\partial \tau}\right|_{\tilde{\tau}}>0,\left.\quad \frac{\partial W_{b}}{\partial \tau}\right|_{\tilde{\tau}}<0 .
$$

This leads to the following proposition.

Proposition 3 There is a range of trade costs for which economic integration (a fall in $\tau$ ) reduces welfare in the larger country but increases welfare in the smaller country. Proof: See the appendix.

Proposition 3 is explained from the fact that both the competition effect and the consumer-price effect are weaker for the small country. The smaller country is the less attractive location from the perspective of firms, but it also has fewer consumers and therefore has a smaller incentive to grant location subsidies. For this reason, the $b$ 's welfare level $W_{b}$ reaches its minimum at a higher level of trade costs as compared to 
Figure 3: Welfare effects of economic integration

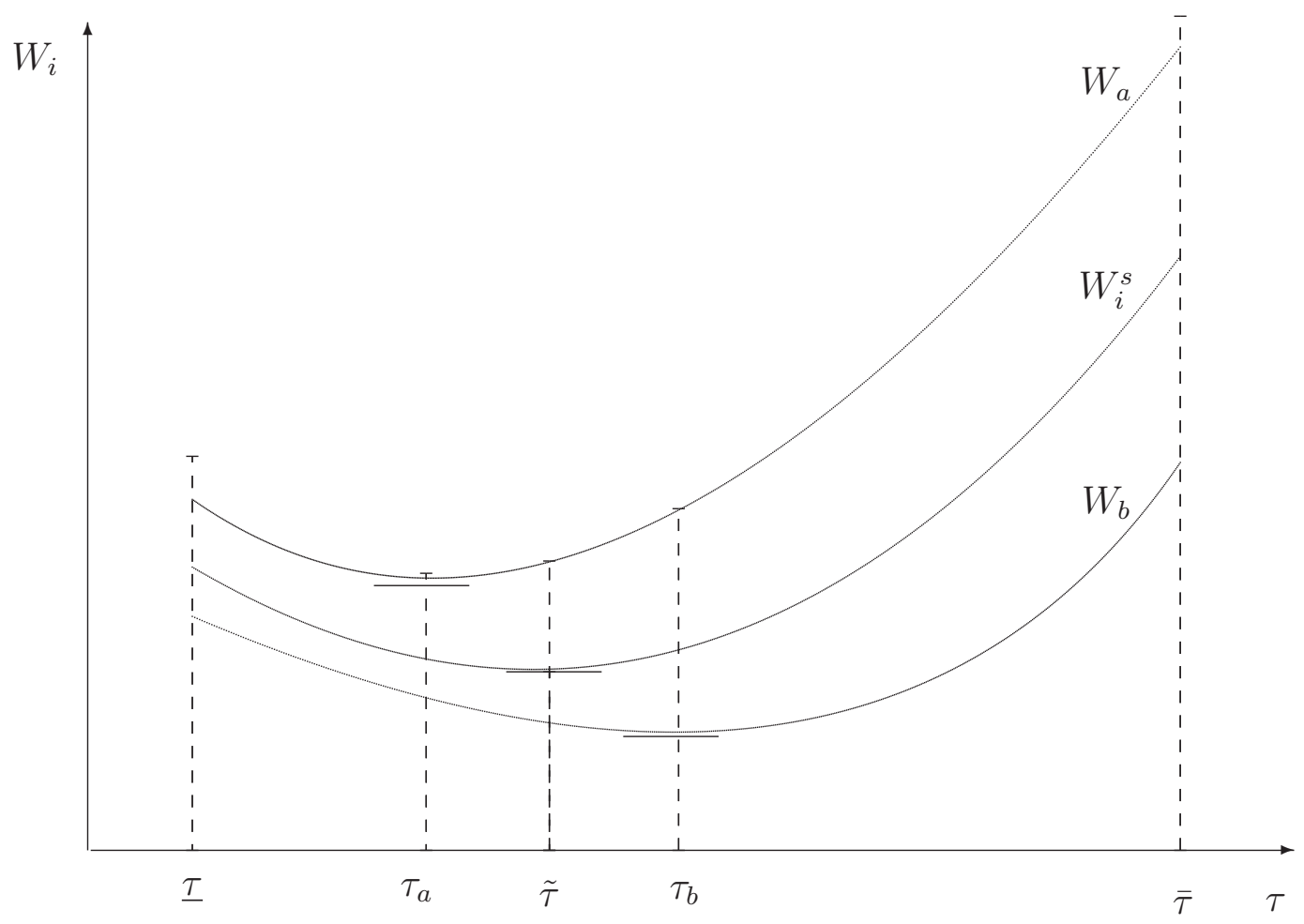

$W_{a}$. Figure 3 illustrates these results. In the graph, economic integration has opposing welfare effects on the two countries if trade costs are in the range $\tau_{a}<\tau<\tau_{b}$, where $\tau_{i}$ is the turning point of $W_{i}$ with respect to $\tau$.

Finally, we illustrate the results of our basic model by means of a simulation analysis. The results are summarised in Table 3 . The table shows that country $b$ 's tax rate turns negative at a higher level of trade costs, $\tau_{b}^{*} \approx 0.27$ than that of country $a$, which turns negative at $\tau_{a}^{*} \approx 0.17$. Consequently, for values of $\tau$ in the interval $(0.17,0.27)$, a fall in trade costs lowers welfare in country $a$, but raises welfare in country $b$. In this particular numerical example, the upper limit of trade costs that still ensures non-negative aftertax profits is $\bar{\tau} \approx 0.68$. At this level of trade costs, the tax rates as a percentage of gross profits (given in the last two columns of the table) approach unity for both the large and the small country. On the other hand, the lower limit for $\tau$ that ensures a non-negative number of firms in the smaller country is $\underline{\tau} \approx 0.10$.

We can compare these numerical results of our model with the empirical evidence on the development of statutory and effective average tax rates, as given in Table $1 .{ }^{19}$

\footnotetext{
${ }^{19}$ The effective average tax rate (EATR) is computed as a weighted average of the statutory tax
} 
Table 3: Simulation results for the basic model

\begin{tabular}{|l|rr|rr|rrr|rr|}
\hline$\tau$ & $t_{a}$ & $t_{b}$ & $W_{a}$ & $W_{b}$ & $m$ & $\pi^{a}$ & $\pi^{b}$ & $t_{a} / \pi_{a}$ & $t_{b} / \pi_{b}$ \\
\hline \hline 0.680 & 0.318 & 0.260 & 12.162 & 11.608 & 5.675 & 0.319 & 0.261 & 0.998 & 0.998 \\
0.550 & 0.191 & 0.143 & 11.237 & 10.534 & 5.846 & 0.279 & 0.231 & 0.687 & 0.622 \\
0.450 & 0.115 & 0.075 & 10.766 & 9.982 & 6.045 & 0.253 & 0.214 & 0.454 & 0.352 \\
0.350 & 0.057 & 0.026 & 10.415 & 9.667 & 6.357 & 0.233 & 0.202 & 0.245 & 0.128 \\
0.250 & 0.018 & -0.005 & 10.218 & 9.590 & 6.920 & 0.217 & 0.195 & 0.081 & -0.025 \\
0.200 & 0.005 & -0.013 & 10.178 & 9.641 & 7.412 & 0.212 & 0.193 & 0.023 & -0.069 \\
0.150 & -0.003 & -0.017 & 10.176 & 9.752 & 8.233 & 0.207 & 0.193 & -0.016 & -0.088 \\
0.100 & -0.007 & -0.016 & 10.213 & 9.922 & 9.874 & 0.204 & 0.194 & -0.034 & -0.082 \\
\hline
\end{tabular}

numerical specification: $k=10, \quad \alpha-w=5, \quad n=0.6, \quad \beta=1$

By both measures, corporate taxation has declined since 1985 in both large and small countries. This is consistent with the results of our model in the earlier phases of economic integration. Moreover, at each point in time, the average tax rate levied by large countries is higher than that of small countries, as stated in our Proposition 2. Finally, a closer look at the time pattern of tax adjustments shows that in 1985, at the onset of economic integration, tax rates were at a "maximum" level that was similar for large and small countries. In the early phases of economic integration, tax rates fell more in the small countries, leading to a substantial tax gap between large and small countries by 1995. As economic integration continued, the large countries also cut their tax rates and the tax gap between large and small countries narrowed during the period 1995-2005. The last two columns of Table 3 show that the initial widening and later narrowing of this tax gap is compatible with the results of our model, if the lump-sum taxes on each firm (which have been used for tractability reasons in our theoretical analysis) are transformed into ad valorem profit taxes.

rate and the effective marginal tax rate (EMTR). In contrast to the EMTR, which measures the tax burden on a marginal investment project that just earns a competitive rate of return, the EATR also includes the taxation of pure economic profit. This makes it the most relevant measure for analysing the discrete location choices of profit-making firms. See Devereux et al. (2002) for more details. 


\section{Domestic profit income and distortionary taxes}

We now consider two extensions to the model. First, we change the ownership structure of firms by letting all (after-tax) profit income accrue to the residents of the host countries. Additionally, we force governments to use distortionary taxes in order to finance subsidies to firms. As both of these extensions increase the complexity of the algebra, we restrict the analysis to our benchmark case of symmetric countries.

In this setting, the residents of each country own $k / 2$ firms and receive the resulting profit income after taxes. Since after-tax profits are equalised by mobile firms, the location of firms does not matter for the distribution of profits. Total after-tax profit income in country $i$ is

$$
\Pi_{i}=\frac{k}{2}\left(\pi_{a}-t_{a}\right)=\frac{k}{2}\left(\pi_{b}-t_{b}\right)
$$

where $\pi_{a}$ and $\pi_{b}$ are given in (8). These profit incomes expand the individual budget constraints in (2) but, due to the quasi-linear specification of utility, do not change the individual and market demands for good $x$ [eqs. (3)-(4)].

We weight tax revenue in each country by an exogenous factor $\lambda \geq 1$. This captures the fact that governments typically do not have access to lump-sum taxes in order to pay subsidies to firms, but must resort to distortionary taxes on personal income or commodity purchases. Hence $(\lambda-1)$ represents the excess burden of this alternative tax instrument. In the opposite case where equilibrium taxes on firms are positive, distortionary taxes can be reduced and the value of one unit of profit-tax revenue is once again given by $\lambda .^{20}$

With these specifications, national welfare in countries $a$ and $b$ is given by

$$
W_{a}=S_{a}+\Pi_{a}+\lambda T_{a}, \quad W_{b}=S_{b}+\Pi_{b}+\lambda T_{b}
$$

Substituting (10), (12) and (32) into (33) and evaluating all terms under symmetry $(n=0.5)$ gives the following equilibrium tax rate, which is derived in the appendix:

$$
\tilde{t}=\frac{k \tau}{(k+1) \beta \lambda}\left[\tau\left(\lambda-\frac{1}{2}\right)-\frac{2(\alpha-w)-\tau}{4(k+1)}\right] .
$$

The structure of the expression in equation (34) is very similar to that in the benchmark analysis [eq.(16)]. The two main differences reflecting the changes in assumptions are

\footnotetext{
${ }^{20}$ See e.g. Keen and Lahiri (1998) for a similar procedure.
} 
both incorporated in the first term in the square bracket (the competition effect). On the one hand, the benefits from taxing profit income are now reduced because, in the symmetric equilibrium, one half of the incidence of the tax falls on domestic capital owners. On the other hand, the gains from taxation are increased, because each unit of tax revenue now receives a value above one in the national welfare function. If the excess burden is sufficiently high $(\lambda>1.5)$ the latter effect dominates and the critical value of $\tau^{*}$ in Figure 1 moves to the left. In the reverse case where $\tau<1.5$, positive tax rates will now be levied only for a smaller range of high trade costs. In any event, the positive competition effect will still be present in this extended model, because each country's profit tax will partly fall on foreign capital owners.

\section{Discussion}

The model presented above combines two strands of research; linking tax/subsidy competition for a small number of firms (monopoly or duopoly) with new economic geography focusing on patterns of agglomeration in multi-firm settings. In the following we relate our results to each of these literatures, starting with the former.

Note first that the use of calculus in the present paper carries the implicit assumption that the number of firms changes continuously in response to tax changes. This is clearly inappropriate when the number of firms is small and the relocation of a single firm involves a discrete change in the location equilibrium. This is most obvious with a monopoly $(k=1)$. In that case, the equilibrium tax formula in eq. (16) exhibits a competition effect, as the analysis implicitly assumes that this firm is divisible. However, in the "true" model such a single, indivisible firm will not face any competition if it relocates to the other country. Hence models of competition for a monopoly firm do not have a competition effect. This explains why such models typically feature negative tax rates in equilibrium (see, e.g., Haaparanta, 1996; Fumagalli, 2003; Davies, 2005).

The competition effect first arises with two firms; either when there is a pre-existing firm in one of the two countries (Bjorvatn and Eckel, 2006) or when the countries compete for two mobile firms (Ferrett and Wooton, 2005). These results are generalised in our setting where the equilibrium tax rate is a rising function of the number of mobile firms $k$ [see eq. (20) and Proposition 1]. Moreover, as in Ferrett and Wooton (2005), it is 
possible in our analysis that all gross profits can be extracted by the host countries, even if they set tax rates non-cooperatively. This is the case whenever the constraint on net profits [eq. (18)] is binding, which will be more likely the larger the number of mobile firms.

In contrast to the models of tax competition under monopolistic or duopolistic market structures, our analysis derives equilibrium tax rates as a continuous function of exogenous model parameters. This allows us to also compare our results to those found in the new economic geography literature. These latter models generally distinguish between two qualitatively different regimes. If all firms are concentrated in one country they earn agglomeration rents that can be fully taxed away by the country that hosts this core (Baldwin and Krugman, 2004). If instead firms are regionally dispersed in the locational equilibrium, then the corresponding equilibrium tax rates in both countries will be negative (Ottaviano and van Ypersele, 2005). ${ }^{21}$ In the present model, in contrast, location rents can arise and tax rates can be positive, even if the equilibrium features a completely symmetric distribution of firms. The core difference is that the number of firms is exogenously fixed in our analysis and firms make positive profits in equilibrium. In contrast the new economic geography models typically assume endogenous market entry, which drives each firm's profit to zero. In that case, no taxable location rent can arise in either country, and the competition effect accordingly disappears. ${ }^{22}$

The competition effect is also crucial in explaining contrasting conclusions with respect to the effects of economic integration. In the full agglomeration case of Baldwin and Krugman (2004), the taxable agglomeration rent earned by firms in the core country is concave (bell-shaped) in the level of trade costs. This implies that economic integration may lead to rising tax rates in the core countries before tax rates eventually fall. In contrast, tax rates are a convex function of trade costs in the present model and economic integration leads to falling tax rates throughout the range where the taxes

\footnotetext{
${ }^{21}$ See their Proposition 3. Note that there is an error in part (i) of this proposition. In the case where countries are equal-sized, equilibrium tax rates will be negative (and not zero) in both countries. Together with their Proposition 3 (ii) this implies that taxes will be negative in any interior locational equilibrium with a positive number of firms in each country. We thank Tanguy van Ypersele for clarifying discussions on this issue.

${ }^{22}$ Effectively profits are turned into capital income in the new economic geography models. These capital incomes, however, are not affected by the lump-sum tax on firms.
} 
are positive. The difference is most obvious at the maximum level of trade costs. In the economic geography setting, this upper bound represents a no-trade condition where no location rents arise and equilibrium tax rates are zero. Hence agglomeration rents and positive tax rates can only arise for trade costs below this critical threshold. In the present model, in contrast, the upper bound on trade costs represents a non-negativity condition for net profits [eq. (18)]. Hence tax rates are at a maximum at this level of trade costs.

We have already discussed the empirical evidence collected in Table 1 . This shows that, in the two decades since 1985, economic integration has led to a reduction in statutory and effective corporate tax rates in small and large countries alike. This finding is consistent with the results of our model but it contradicts the theoretical prediction that the economic geography models of tax competition derive for the large ("core") countries in the agglomerated equilibrium.

Finally we briefly compare our results to those derived in models of asymmetric tax competition when capital markets are perfectly competitive (Bucovetsky, 1991; Wilson, 1991). A result that holds for both competitive and imperfectly competitive capital markets is that small countries levy lower tax rates. This result is also in line with the empirical evidence (see Table 1). There are important differences, however. Firstly, with competitive markets the equilibrium location of capital depends only on tax rates, with the smaller country attracting a more than proportionate share of capital due to it underbidding its larger neighbour. In contrast, the location pattern for mobile firms is much richer in the present model and depends on market size and competition effects, in addition to tax differences. Secondly, neither the competition effect nor the consumerprice effect is present in a model with perfectly competitive capital markets. Hence capital tax rates will be zero in such a model when lump-sum taxes are simultaneously available. ${ }^{23}$ This implies in particular that a switch from positive to negative tax rates, which is a characteristic result of our model (see Proposition 1), cannot arise in a setting with perfectly competitive capital markets.

\footnotetext{
${ }^{23}$ In the models of Bucovetsky (1991) and Wilson (1991) positive tax rates are instead enforced by the assumption that source-based capital taxes are the only tax instrument to finance a public good.
} 


\section{Conclusion}

In this paper we have set up a simple model where two countries of different size compete for the location of an exogenously determined, but variable, number of profitmaking firms in an oligopolistic industry. This model has allowed us to derive closedform solutions both for the equilibrium allocation of firms and for the tax rates charged by each country. A special feature of the model is that taxable location rents can arise even in an interior location equilibrium where firms are dispersed. At the same time national governments have the incentive to attract internationally mobile firms by means of subsidies, in order to save on trade costs. Whether taxes are positive or negative in the location equilibrium depends on the interplay of these two counteracting forces.

Our analysis has led to two main results. First, economic integration leads to a $U$ shaped relationship between the degree of economic integration and the level of equilibrium taxes in both the large and the small country. In this process there is a critical level of trade costs where tax rates switch from positive to negative. This result may be indicative of the actual policy experience where a combination of falling statutory and effective corporate taxes, the proliferation of preferential tax regimes for internationally mobile firms, and the increasingly widespread use of investment subsidies have, in sum, led to net effective tax payments of mobile firms that are close to zero or even negative. Also most observers seem to expect that this trend will continue as global economic integration proceeds further, despite some attempts at policy coordination among the EU and OECD member states.

A second main result of our model is that economic integration can simultaneously benefit small countries and harm large countries. This result may be relevant for several of the recent policy debates in the area of international tax coordination, such as the EU's interest withholding tax directive or the elimination of "harmful tax practices", pursued simultaneously by the European Union (Primarolo Report, 1999) and the OECD (2000). To a large extent, these policy initiatives are targeted against small tax havens. This demonstrates that there are conflicting interests between large countries,

which favour coordination measures to cushion the effects of economic integration, and the small countries that do not. 


\section{Appendix}

\section{Derivation of equation set (22)}

Substituting $m$ from (10) into (14) and rearranging gives each country's best response function

$$
\begin{aligned}
& t_{a}=\frac{2 \tau^{2} k}{\beta[4(k+1)-n]}+\frac{\tau \mu\{(2 n-1)[2(k+1)-n]-n k\}}{\beta(k+1)[4(k+1)-n]}+t_{b} \frac{[2(k+1)-n]}{[4(k+1)-n]}, \\
& t_{b}=\frac{2 \tau^{2} k}{\beta[4(k+1)-u]}-\frac{\tau \mu\{(2 n-1)[2(k+1)-u]+u k\}}{\beta(k+1)[4(k+1)-u]}+t_{a} \frac{[2(k+1)-u]}{[4(k+1)-u]}
\end{aligned}
$$

where $\mu \equiv[2(\alpha-w)-\tau]>0$ and $u \equiv(1-n)$. Solving the set of simultaneous equations (A.1) yields the reduced-form expressions for the Nash equilibrium taxes in the asymmetric equilibrium, given in (22).

\section{Proof of Proposition 3}

Substituting (22) and (26) in country a's welfare function [eq. (13)] and differentiating with respect to $\tau$ gives

$$
\frac{\partial W_{a}}{\partial \tau}=\frac{\partial S_{a}}{\partial \tau}+t_{a} \frac{\partial m}{\partial \tau}+m \frac{\partial t_{a}}{\partial \tau}
$$

Performing the derivations gives, in a first step

$$
\begin{gathered}
\frac{\partial W_{a}}{\partial \tau}=\frac{\tau\left[2 m k(k+1)+n k^{2}-n m(k-m)\right]-n k^{2}(\alpha-w)}{\beta(k+1)^{2}} \\
-\frac{t_{a}(2 n-1)(3 k+2)(\alpha-w)}{\tau^{2}(6 k+5)}+\frac{(2 n-1)(3 k+2)[2 k+2-n] m(\alpha-w-\tau)}{\beta(k+1)^{2}(6 k+5)} .
\end{gathered}
$$

It is easily checked that this expression reduces to (29) when countries are symmetric ( $n=0.5$ and hence $m=k / 2)$.

Evaluating (A.2) at $\tilde{\tau}$, as given in (30), yields

$$
\begin{gathered}
\left.\frac{\partial W_{a}}{\partial \tau}\right|_{\tilde{\tau}}=\frac{(\alpha-w)(2 n-1) \Omega_{a}}{\beta(k+1)^{2}(6 k+5)} \quad \text { where } \\
\Omega_{a} \equiv \frac{2 k(k+1)\left(12 k^{2}+33 k+18\right)}{8 k+11}+\frac{k(3 k+2)[n+(k+1)(4 n-1)]}{2}+\frac{(2 n-1)(8 k+9)^{2}}{4(8 k+11)(6 k+5)} \\
+\frac{(3 k+2)[2(k+1)-n]\left[k\left(48 k^{2}+82 k+35\right)-(2 n-1)\left(48 k^{2}+86 k+36\right)\right]}{2(6 k+5)(8 k+11)} .
\end{gathered}
$$

Since $\Omega_{a}>0$ for all $k>1$ and $n>0.5$ by assumption, it follows that $\partial W_{a} /\left.\partial \tau\right|_{\tilde{\tau}}>0$. 
For country $b$ we proceed analogously. Using (22) and (26) in $W_{b}$ [eq. (13)] and differentiating with respect to $\tau$ gives

$$
\frac{\partial W_{b}}{\partial \tau}=\frac{\partial S_{b}}{\partial \tau}-t_{b} \frac{\partial m}{\partial \tau}+(k-m) \frac{\partial t_{b}}{\partial \tau} .
$$

Performing the derivations yields

$$
\begin{aligned}
& \frac{\partial W_{b}}{\partial \tau}=\frac{\tau\left[(k-m) k(2 k+2+n)+m^{2}(1-n)\right]-k(\alpha-w)[(1-n) m+n(k-m)]}{\beta(k+1)^{2}} \\
+ & \frac{t_{b}(2 n-1)(3 k+2)(\alpha-w)}{\tau^{2}(6 k+5)}-\frac{(2 n-1)(k-m)(\alpha-w-\tau)[2(k+1)+n(3 k+2)]}{\beta(k+1)^{2}(6 k+5)},
\end{aligned}
$$

which again reduces to $(29)$ when $n=0.5$.

Evaluating (A.3) at $\tilde{\tau}$ gives

$$
\begin{gathered}
\left.\frac{\partial W_{b}}{\partial \tau}\right|_{\tilde{\tau}}=\frac{-(\alpha-w)(2 n-1) \Omega_{b}}{\beta(k+1)^{2}(6 k+5)} \quad \text { where } \\
\Omega_{b} \equiv \frac{24 k^{3}+19 k^{2}-2 k+2(1-n)(8 k+9)(3 k+2)\left(8 k^{2}+8 k-m\right)}{4(8 k+11)} \\
+\frac{(3 k+2)}{4}\left\{k[4(k+1)(2 n-1)+n]+\frac{(2 n-1)(8 k+9)[2(k+1)+n(3 k+2)]}{(6 k+5)}\right\} \\
+\frac{(8 k+7)[2(k+1)+n(3 k+2)](k-m)}{8 k+11} .
\end{gathered}
$$

Since $\Omega_{b}>0$ from $k>1, n>0.5$ and $k>m$, it follows that $\partial W_{b} /\left.\partial \tau\right|_{\tilde{\tau}}<0$, as stated in (31).

\section{Derivation of equation set (34)}

We start from the following expressions for national welfare

$$
W_{a}=S_{a}+\Pi_{a}+\lambda t_{a} m, \quad W_{b}=S_{b}+\Pi_{b}+\lambda t_{b}(k-m) .
$$

Substituting in from (10), (12) and (32) and evaluating all terms at $n=0.5$ gives for country $i$ 's best response function $(i, j \in\{a, b\}, i \neq j)$

$\frac{t_{i} \beta}{8 \tau^{2}}[8 \lambda(k+1)-(2 k+1)]=\frac{k}{2}\left[\lambda-\frac{1}{2}-\frac{[2(\alpha-w)-\tau]}{4 \tau(k+1)}\right]+\frac{t_{j} \beta}{8 \tau^{2}}[4 \lambda(k+1)-(2 k+1)]$.

Combining the two best responses and manipulating terms yields the Nash equilibrium tax rates given in (34). 


\section{References}

Baldwin, R.E. and P. Krugman (2004), Agglomeration, integration and tax harmonisation. European Economic Review 48, 1-23.

Bjorvatn, K. and C. Eckel (2006), Policy competition for foreign direct investment between asymmetric countries. European Economic Review 50, 1891-1906.

Black, D.A., Hoyt, W.E. (1989), Bidding for firms. American Economic Review 79, 1249-1256.

Borck, R. and M. Pflüger (2006), Agglomeration and tax competition. European Economic Review 50, 647-668.

Brander, J.A. and P.R. Krugman (1983), A 'Reciprocal Dumping' Model of International Trade. Journal of International Economics 15, 313-323.

Bucovetsky, S. (1991), Asymmetric tax competition. Journal of Urban Economics 30, $167-181$.

Burbidge, J., K. Cuff and J. Leach (2006), Tax competition with heterogeneous firms. Journal of Public Economics 90, 533-549.

Davies, R.B. (2005), State tax competition for foreign direct investment: A winnable war? Journal of International Economics 67, 498-512.

Devereux, M.P., R. Griffith and A. Klemm (2002), Corporate income tax reforms and international tax competition. Economic Policy 35, 451-495.

Ferrett, B. and I. Wooton (2005), Competing for a duopoly: international trade and tax competition. CEPR Discussion Paper 5379, London.

Fuest, C. (2005), Economic integration and tax policy with endogenous foreign firm ownership, Journal of Public Economics 89, 1823-1840.

Fumagalli, C. (2003), On the welfare effects of competition for foreign direct investment. European Economic Review 47, 963-983. 
Haaparanta, P. (1996), Competition for foreign direct investment. Journal of Public Economics 63, 141-153.

Haufler, A. and I. Wooton (1999), Country size and tax competition for foreign direct investment. Journal of Public Economics 71, 121-139.

Hines, J.R. (1999), Lessons from behavioral responses to international taxation. $\mathrm{Na}$ tional Tax Journal 52, 304-322.

Hines, J.R. (2005), Corporate taxation and international competition. Ross School of Business Paper 1026. University of Michigan.

Janeba, E. (1998), Tax competition in imperfectly competitive markets. Journal of International Economics 44, 135-153.

Keen, M. and S. Lahiri (1998), The comparison between destination and origin principles under imperfect competition, Journal of International Economics 45, 323350.

Kind, H.J., K.H. Midelfart Knarvik and G. Schjelderup (2000), Competing for capital in a 'lumpy' world. Journal of Public Economics 78, 253-274.

OECD (2000), Towards global tax co-operation. Progress in identifying and eliminating harmful tax practices. Paris.

Ottaviano G. and T. van Ypersele (2005), Market size and tax competition. Journal of International Economics 67, 25-46.

Primarolo Report (1999), Report from the Code of Conduct Group to the ECOFIN Council, 29 November 1999.

Wilson, J.D. (1991), Tax competition with interregional differences in factor endowments. Regional Science and Urban Economics 21, 423-451. 